\title{
Comparison of efficacy and safety of second-line palliative chemotherapy with paclitaxel plus raltitrexed and paclitaxel alone in patients with metastatic gastric adenocarcinoma: a randomized phase 2 clinical trial
}

\section{XIAOYING ZHAO}

Fudan University Shanghai Cancer Center

\section{Zhiyu CHEN}

Fudan University Shanghai Cancer Center

Xiaowei ZHANG

Fudan University Shanghai Cancer Center

Xiaodong ZHU

Fudan University Shanghai Cancer Center

Wen ZHANG

Fudan University Shanghai Cancer Center Lixin QIU

Fudan University Shanghai Cancer Center Chenchen WANG

Fudan University Shanghai Cancer Center Mingzhu HUANG

Fudan University Shanghai Cancer Center Zhe ZHANG

Fudan University Shanghai Cancer Center

Wenhua LI

Fudan University Shanghai Cancer Center

Lei YANG

Nantong Tumor Hospital

Jin LI

Fudan University Shanghai Cancer Center

Weijian GUO ( $\nabla$ guoweijian1@hotmail.com )

Fudan University Shanghai Cancer Center 
Keywords: gastric adenocarcinoma, raltitrexed, paclitaxel, second-line palliative chemotherapy

Posted Date: September 1st, 2020

DOI: https://doi.org/10.21203/rs.3.rs-61550/v1

License: (c) (i) This work is licensed under a Creative Commons Attribution 4.0 International License. Read Full License 


\section{Abstract}

\section{Background}

Paclitaxel is a microtubule stabilizing agent, used as standard second line chemotherapy in the treatment of advanced gastric cancer. This study was designed to compare the clinical outcome of paclitaxel plus raltitrexed regimen as second line treatment in MGC patients.

\section{Methods}

An open, randomized, multi centers phase II clinical trial. 148 patients were randomly assigned and treated with either RP (raltitrexed $3 \mathrm{mg} / \mathrm{m}^{2}$ day 1 and paclitaxel $135 \mathrm{mg} / \mathrm{m}^{2}$ day 1 , 3week) or P (paclitaxel $135 \mathrm{mg} / \mathrm{m}^{2}$ day 1 , 3week) as second-line palliative chemotherapy. The primary endpoint is PFS; secondary endpoint is ORR, OS and safety.

Results

Progression free survival has a tendency to be prolonged with RP versus $P(2.7$ month vs. 1.7 month, $p=$ $0.148)$. Overall survival has also a tendency to be prolonged with RP versus $P$ (10.2month vs. 6.1 month, $p=0.140)$. Overall response rate was equal with $R P$ versus $P(6.8 \%$ vs. $4.0 \%, p=0.72)$. DCR in the RP and $P$ group was $56.2 \%$ and $36.0 \%$ respectively. Grade 3 to 4 treatment-related adverse events occurred in $36.2 \%(\mathrm{RP})$ vs. $28.2 \%(\mathrm{P})$ of patients. Frequent grade 3 to 4 toxicities for RP vs. P were: neutropenia ( $11.0 \%$ vs. $4.0 \%$ ), anemia ( $1.4 \%$ vs. $4.0 \%$ ), thrombocytopenia (1.4\% vs. $5.3 \%)$, and all grade peripheral neurotoxicity ( $12.3 \%$ vs. $17.3 \%$ ). All grades found with elevated aminotransferase ( $27.4 \%$ vs. $14.1 \%)$. Subgroup analysis shows if the disease combined with ascites or peritoneal involved OS of RP regimen is longer $(p=0.05)$.

\section{Conclusions}

Second-line palliative chemotherapy with paclitaxel plus raltitrexed have tendency to prolong PFS and OS, especially some patients with ascites or peritoneal involved, which needs to be confirmed by larger sample studies.

Trial registration

NCT02072317. Registered 26 February 2014

\section{Background}

Gastric cancer is the fifth most common malignancy worldwide. The highest incidence is seen in East Asian countries especially in China and Japan [1,2]. More than 679,000 new gastric cancer diagnoses were recorded in China in 2015 [3]. Advanced gastric cancer patients have a poor prognosis with a median survival time, if untreated, of 3 to 5 months. Unfortunately, although chemotherapy has shown a 
significant survival benefit, the 5-year OS rate of the advanced gastric cancer is less than 5\% [4]. The recommended first-line chemotherapy for patients with HER2-negative gastric cancer is combination of oxaliplatin or cisplatin plus 5-FU or capecitabine. For HER2-positive gastric cancer, the ToGA study showed that trastuzumab should be added to the first-line cytotoxic therapy $[5,6]$. In the second-line therapy setting, ramucirumab is the only molecular-targeted drug in a global phase III clinical trial [7]. Single docetaxel, irinotecan, and paclitaxel have significantly prolonged OS compared with best supportive care (BSC). Previous clinical studies of second-line combination chemotherapy have not improved the efficacy $[8,9]$.

Thymidylate synthase is a well-established target enzyme for the therapy of gastric cancers. The mechanism of 5-fluorouracil ( $5 \mathrm{FU}$ ) resistance was investigated, focusing on the level of thymidylate synthase (TS) ternary complex formed with fluoro-deoxyuridine monophosphate (FdUMP) [10, 11, 12]. Raltitrexed is a specific TS inhibitor which doesn't requires modulation effects on RNA $[13,14,15]$. A meta-analysis included 11 studies with 4622 CRC patients leads to an equivalent overall survival and response rates with acceptable toxicities comparing with traditional 5-fluorouracil-based regimen and raltitrexed-based regimen $[16,17,18,19,20]$. There is no cross-resistance between raltitrexed and fluorouracil is reported [21.22.23]. This study was designed to compare the efficacy and safety of secondline palliative chemotherapy with paclitaxel plus raltitrexed and paclitaxel alone in patients with metastatic gastric adenocarcinoma who have failed to receive 5-fluorouracil treatment in 1 st line regimen.

\section{Methods}

\section{Patient Screening}

Patient inclusion criteria set were: age $\leq 18$ years ; histologically proven gastric or esophagogastric junction adenocarcinoma; measurable and/or assessable metastatic disease according to RECIST 1.0 criteria, or locally recurrent disease associated with one or more measurable lymph nodes; ECOG performance status > 2; progression from front-line chemotherapy with XELOX or FOLFOX (HER2-positive could add trastuzumab); 6 weeks or longer from prior radiotherapy and 3 weeks or longer from surgery; adequate hepatic, renal, and hematologic function. Similarly, exclusion criteria set were: concurrent cancer, neuropathy, brain, or leptomeningeal involvement, uncontrolled significant comorbid conditions, or if patient could not comprehend the purpose of the study and could not comply with its requirements. The study was conducted in full accordance with the International Conference on Harmonization Good Clinical Practice guidelines and the Declaration of Helsinki and was approved by the ethics committee of the provincial government of Innsbruck on August, 2012. All the participants were provided with written informed consent before enrolment and commencement of the study.

\section{Stratification and Treatment}

This is a randomized, multicenter, open-label, phase II clinical study in patients with histologically proven, inoperable, locally advanced or metastatic gastric cancer. Patients were randomly assigned (1:1) to 
receive RP (raltitrexed $3 \mathrm{mg} / \mathrm{m}^{2} \mathrm{~d} 1$ and paclitaxel $135 \mathrm{mg} / \mathrm{m}^{2} \mathrm{~d} 1,3 \mathrm{w}$ ) or $\mathrm{P}$ (paclitaxel $135 \mathrm{mg} / \mathrm{m}^{2} \mathrm{~d} 1,3 \mathrm{w}$ ) as second-line palliative chemotherapy. Dose modification criteria were predefined. Treatment continued until disease progression, unacceptable toxicity, and death or consent withdrawal. The continuity of treatment can be discontinue maximum of 10 cycles or as per of PI decision.

\section{Evaluation and Outcomes}

Before randomization, a complete medical history and physical examination were undertaken, including $\mathrm{CBC}$, blood chemistries, and tumor assessments. Tumor measurements were undertaken every 6 weeks until progression found in both arms and were assessed by RECIST 1.0 criteria. PFS was measured from date of randomization to first radio graphically documented progressive disease (PD) or death due to any cause. OS time was measured from date of randomization to date of death from any cause. Toxicities were graded according to the National Cancer Institute of Canada Common Toxicity Criteria, version 3.0. Quality of life was assessed at the same time as tumor assessments and data were collected every 3 months after disease progression, using the European Organization for Research and Treatment of Cancer Quality of Life Questionnaire (QLQ) -C30, version 3.

\section{Statistical Analysis}

The primary endpoint PFS, secondary endpoint OS, ORR and safety were measured statistically. The Kaplan-Meier statistical method was used to calculate PFS and OS. Overall response rates were compared using $\mathrm{X}^{2}$ test. PFS and OS were calculated on the basis of predefined full analysis population (all randomly assigned and treated patients). Patients were considered assessable for response if they received two or more chemotherapy cycles. Safety analyses included for all the treated patients; involved the analysis of treatment based adverse events, including events possibly or probably related to study medication and those regardless of causality.

\section{Results}

\section{Patients}

A total of 148 patients $(R P=73 ; P=75)$ were randomly assigned between August 2014 and December 2017. All the patients were received the medication as per designed protocol and the outcome was analyzed for efficacy and safety. The majority of patients were males than females (94 vs. 54). More than $90 \%$ patients were score ECOG 1.Both treatment groups were well balanced for baseline characteristics (Table 1).

\section{Treatment}

The median duration of therapy was 3.5 cycles with RP (range, 1 to 15 cycles) and 4 cycles with P (range, 1 to 12 cycles). Dose reductions occurred in 12 patients with RP (16.4\%) and 8 patients with $\mathrm{P}(10.7 \%)$. Neutropenia and thrombocytopenia were the most prominent adverse events leading to cycle delay and 
dose reduction in RP and P. The most common adverse event leading to dose reduction was neutropenia for RP. The main reason for therapy discontinuation was progressive disease in both groups.

\section{Efficacy: Secondary End Point (OS and PFS)}

At a median follow-up time of 13 months, In ITT population the median OS was longer with RP versus $\mathrm{P}(10.2$ months; $95 \% \mathrm{Cl}, 8.2$ to 12.2 ; vs. 6.1 months; $95 \% \mathrm{Cl}, 4.4$ to 7.8 ; $\log$-rank $\mathrm{p}=0.14)$, but no statistical differences (Fig. 1). Progression free survival was similar with RP versus $\mathrm{P}(2.7$ months; $95 \% \mathrm{Cl}, 2.1$ to 3.8 ; vs. 1.7 months; $95 \% \mathrm{Cl}, 1.4$ to 2.0; log-rank $\mathrm{p}=0.148$ ) (Fig. 2). In PP population, the median OS was longer with RP versus $\mathrm{P}(10.8$ months; $95 \% \mathrm{Cl}, 9.5$ to 12.1 ; vs. 6.9 months; $95 \% \mathrm{Cl}, 4.2$ to 9.6 ; log-rank $\mathrm{p}=0.21)$, but no statistical differences (Fig. 3). Progression free survival was similar with RP versus P (3.0 months; $95 \% \mathrm{Cl}, 2.4$ to 3.5 ; vs. 1.9 months; $95 \% \mathrm{Cl}, 1.6$ to 2.2 ; log-rank $\mathrm{p}=0.22$ ) (Fig. 4).

We also found no significant difference between different tumor site and prior chemotherapy. But in patients with more than two organs involved, progression free survival was slightly longer in RP versus $\mathrm{P}$ (2.8 months; $95 \% \mathrm{Cl}, 2.2$ to 3.5 ; vs. 1.9 months; $95 \% \mathrm{Cl}, 1.6$ to 2.3 ; log-rank $\mathrm{p}=0.09$ ).

\section{Efficacy: Secondary End Point (Overall Response Rate)}

The overall confirmed response rate was equal with RP (6.8\%) versus XELOX (4.0\%) (25\%; P = 77;

Table 2). One patient got CR in P group. The Partial response rate was $6.8 \%$ in RP and $2.7 \%$ in P. The DCR was $56.2 \%$ in RP group and $36 \%$ in $P$ group.

\section{Safety: Secondary End Point}

Grade 3 to 4 treatment-related adverse events occurred in $60.6 \%(\mathrm{RP})$ vs. $57.5 \%(\mathrm{P})$ of patients. Frequent toxicities in grade 3 to 4 for RP vs. P were: neutropenia (11\% vs. $4 \%$ ), no febrile granulocyte deficiency found in either of group, anemia (1.4\% vs. $4 \%$ ), thrombocytopenia ( $1.4 \%$ vs. $5.3 \%)$, and all grade peripheral neurotoxicity (1.4\% vs. $2.7 \%$ ). Major treatment-based adverse events were summarized in Table 3.

Analysis of baseline characteristics and all survival time shows if the pathological condition is poor, RP regimen maybe more favorable $(p=0.09)$, and if the disease combined with ascites or peritoneal involved or metastasis sites are more than 2 , RP regimen is more beneficial $(p=0.05)$.

\section{Discussion}

Universally, paclitaxel is used as second-line chemo in the treatment of gastric cancer. Ramucirumab is an antagonist of vascular endothelial growth factor receptor 2 (VEGFR2), the combination with paclitaxel can further improve the therapeutic effect. But it is not yet available in the Chinese Market. Previous combined chemotherapies as 2 nd line were not successful, although clinical studies have been reported. Previous Phase II clinical studies of combination of irinotecan and cisplatin or S-1, have failed, this may be because of the platinum or fluorouracil drugs that have failed in the 1 stline. There is no crossresistance observed between raltitrexed and fluorouracil. This study was designed to compare the 
efficacy and safety of second-line palliative chemotherapy with paclitaxel plus raltitrexed and paclitaxel alone in patients with metastatic gastric adenocarcinoma who failed to receive fluorouracil treatment as 1 st line.

In the present study, the combination doses of PTX was adjusted to $240 \mathrm{mg} / \mathrm{m} 2$ with the dosing frequency and interval of three-weekly $\mathrm{d} 1$, d8, and d15 to meet the primary endpoint of PFS. The adjusted dose for treatment was found well tolerated despite of the higher cumulative paclitaxel dose with shorter infusion schedules (30 minutes vs. 3 hours for paclitaxel) delivered without premedication for unselected patients with metastatic gastric cancer. In this study, we chose $135 \mathrm{mg} / \mathrm{m} 2$ PTX and $3 \mathrm{mg} / \mathrm{m} 2$ raltitrexed as study group with the aim to explore whether combination regimen is superior or not in comparison to the single-drug regimen.

As usual, the ORR is low in each group but the DCR was found $56.2 \%$ and $36 \%$ in combination and in single PTX group. Although the OS and PFS was similar not only in ITT but also in PP population, but the absolute increased OS time of ITT was 4.1 months. Subgroup analysis also suggested that if the pathological type is poor RP regimen maybe more favorable $(p=0.09)$, and if the disease combined with ascites or peritoneal involved or disease metastasis sites more than 2 , RP regimen is more beneficial $(p=$ 0.05).

The hematological toxicity of RP group and control group was similar. The incidence of hepatotoxicity was higher in the experimental group because of the combination of raltitrexed.

The survival time of paclitaxel monotherapy group was shorter than 3-4 months reported in previous literatures, probably because this study chose the use of paclitaxel once every three weeks. Clinical study of second-line every three week paclitaxel-albumin in gastric cancer also showed worse efficacy than weekly use. Another reason is that the paclitaxel dosage in this study has chosen the lower limit of the three-week standard dosage regimen, considering the comparability between the experimental group and the single drug group. The application of low-dose paclitaxel in China conforms to the fact that Chinese patients have low physique. Even if lower doses of paclitaxel were chosen in this study, a certain proportion of hematological toxicity was observed. Fortunately, the addition of an antineoplastic agent in the combination group did not significantly increase the hematological toxicity and was well tolerated.

The author thinks that appropriate dosage and usage of paclitaxel and antimetabolites may play greater role in 2 nd line therapy of AGCs. Paclitaxel combined with raltitrexed group still saw a trend of improvement in efficacy with favorable tolerance and good safety, especially in individual sub-groups; it is worth carrying out a randomized controlled study for this subgroup in the future.

\section{Declarations}

\section{Acknowledgments}

This work was supported by the Fudan Research Fund 


\section{References}

1. Ajani JA, Lee J, Sano T, Janjigian YY, Fan D, Song S. Gastric adenocarcinoma. Nat Rev Dis Primers. 2017;3:17036.

2. Balakrishnan M, George R, Sharma A, Graham DY. Changing Trends in Stomach Cancer Throughout the World. Curr Gastroenterol Rep. 2017;19(8):36.

3. Nie Y, Wu K, Yu J, Liang Q, Cai X, Shang Y, et al. A global burden of gastric cancer: the major impact of China. Expert Rev Gastroenterol Hepatol. 2017;11(7):651-61.

4. Lau CH, Wu X, Chung VC, Liu X, Hui EP, Cramer H, et al. Acupuncture and Related Therapies for Symptom Management in Palliative Cancer Care: Systematic Review and Meta-Analysis. Med (Baltim). 2016;95(9):e2901.

5. Van Cutsem E, Sagaert X, Topal B, Haustermans K, Prenen H. Gastric cancer. Lancet. 2016;388(10060):2654-64.

6. Wong NACS, Amary F, Butler R, Byers R, Gonzalez D, Haynes HR, et al. HER2 testing of gastrooesophageal adenocarcinoma: acommentary and guidance document from the Association of Clinical Pathologists Molecular Pathology and Diagnostics Committee. J Clin Pathol. 2018;71(5):388-94.

7. Fuchs CS, Tomasek J, Yong CJ, Dumitru F, Passalacqua R, Goswami C, et al. REGARD Trial Investigators. Ramucirumab monotherapy for previously treated advanced gastric or gastrooesophageal junction adenocarcinoma (REGARD): an international, randomised, multicentre, placebo-controlled, phase 3 trial. Lancet. 2014;383(9911):31-9.

8. IlsonDH. Advances in the treatment of gastric cancer. Curr OpinGastroenterol. 2017;33(6):473-6.

9. Mizrak Kaya D, Harada K, Shimodaira Y, Amlashi FG, Lin Q, Ajani JA. Advanced gastric adenocarcinoma: optimizing therapy options. Expert Rev ClinPharmacol. 2017;10(3):263-71.

10. Wang W, McLeod HL, Cassidy J, Collie-Duguid ES. Mechanisms of acquired chemoresistance to 5fluorouracil and tomudex: thymidylate synthase dependent and independent networks. Cancer Chemother Pharmacol. 2007;59(6):839-45.

11. Chen XD, He FQ, Chen M, Tang LC, Tang XL. Can S-1 replace fluorouracil for advanced gastric cancer? A PRISMA-compliant systematic review and meta-analysis. Med (Baltim). 2016;95(24):e3916.

12. Ajani J. Review of capecitabine as oral treatment of gastric, gastroesophageal, and esophageal cancers. Cancer. 2006;107(2):221-31.

13. Massacesi C, Terrazzino S, Marcucci F, Rocchi MB, Lippe P, Bisonni R, et al. Uridine diphosphate glucuronosyl transferase $1 \mathrm{~A} 1$ promoter polymorphism predicts the risk of gastrointestinal toxicity and fatigue induced by irinotecan-based chemotherapy. Cancer. 2006;106(5):1007-16.

14. Scheithauer W, Kornek GV, Ulrich-Pur H, Penz M, Raderer M, Salek T, et al. Oxaliplatin plus raltitrexed in patients with advanced colorectal carcinoma: results of a Phase I-II trial. Cancer. 2001;91(7):1264-71. 
15. Raderer M, Fiebiger W, Wrba F, Scheithauer W. Fatal liver failure after the administration of raltitrexed for cancer chemotherapy: a report of two cases. Cancer. 2000;89(4):890-2.

16. Barni S, Ghidini A, Coinu A, Borgonovo K, Petrelli F. A systematic review of raltitrexed-based first-line chemotherapy in advanced colorectal cancer. Anticancer Drugs. 2014;25(10):1122-8.

17. Decoster L, Neyns B, Akouaouach H, Fontaine C, Schallier D, De Grève JL. Efficacy of infusional biomodulated 5-fluorouracil in metastatic colorectal cancer after raltitrexed failure. Anticancer Res. 2004;24(3b):2037-40.

18. Vaflard P, Ederhy S, Torregrosa C, André T, Cohen R, Lopez-Trabada D. Fluoropyrimidines cardiac toxicity: 5-fluorouracil, capecitabine, compound S-1 and trifluridine/tipiracil. Bull Cancer. 2018;105(78):707-19.

19. Barni S, Ghidini A, Coinu A, Borgonovo K, Petrelli F. A systematic review of raltitrexed-based first-line chemotherapy in advanced colorectal cancer. Anticancer Drugs. 2014;25(10):1122-8.

20. Papanastasopoulos P, Stebbing J. Molecular basis of 5-fluorouracil-related toxicity: lessons from clinical practice. Anticancer Res. 2014;34(4):1531-5.

21. Shao G, Liu R, Ding W, Lu L, Li W, Cao H, Liu R, Li C, Xiang H, Yang Z, Yang J, Song J, Wang J. Efficacy and safety of raltitrexed-based transarterialchemoembolization for colorectal cancer liver metastases. Anticancer Drugs. 2018;29(10):1021-5.

22. El-Mesallamy HO, El Magdoub HM, Chapman JM, Hamdy NM, Schaalan MF, Hammad LN, Berger SH. Biomolecular study of human thymidylate synthase conformer-selective inhibitors: New chemotherapeutic approach. PLoS One. 2018;13(3):e0193810.

23. Mori R, Futamura M, Tanahashi T, Tanaka Y, Matsuhashi N, Yamaguchi K. YoshidaK. 5FU resistance caused by reduced fluoro-deoxyuridine monophosphate and itsreversal using deoxyuridine. Oncol Lett. 2017;14(3):3162-8.

\section{Tables}

Table 1.Patient and Cancer Baseline Characteristics 


\begin{tabular}{|c|c|c|c|c|c|c|}
\hline \multirow[b]{3}{*}{ Characteristic } & \multicolumn{6}{|c|}{ Treatment(No. of patients) } \\
\hline & \multicolumn{2}{|c|}{$\mathrm{RP}(\mathrm{n}=73)$} & \multicolumn{2}{|c|}{$P(n=75)$} & \multicolumn{2}{|c|}{ Total $(n=148)$} \\
\hline & No. & $\%$ & No. & $\%$ & No. & $\%$ \\
\hline \multicolumn{7}{|l|}{ Sex } \\
\hline male & 48 & 66.0 & 46 & 61.3 & 87 & 63.5 \\
\hline \multicolumn{7}{|l|}{ Age, years } \\
\hline Median & 56.2 & & 53.5 & & 55.3 & \\
\hline Range & $25-71$ & & $27-74$ & & $25-74$ & \\
\hline$<60$ & 63 & 86.3 & 59 & 78.7 & 122 & 82.4 \\
\hline$\geq 60$ & 10 & 13.7 & 16 & 11.3 & 26 & 17.6 \\
\hline \multicolumn{7}{|l|}{ ECOG } \\
\hline 0 & 1 & 1.4 & 2 & 2.7 & 3 & 2.0 \\
\hline 1 & 68 & 93.2 & 69 & 92 & 137 & 92.6 \\
\hline 2 & 4 & 6.4 & 4 & 5.4 & 8 & 5.4 \\
\hline \multicolumn{7}{|c|}{ Primary tumor site } \\
\hline GE junction & 3 & 4.1 & 3 & 4 & 6 & 4.1 \\
\hline Fundus & 5 & 6.8 & 6 & 8 & 11 & 7.4 \\
\hline Antrum & 55 & 75.3 & 49 & 65.3 & 104 & 70.2 \\
\hline Body & 10 & 13.7 & 17 & 22.7 & 27 & 18.2 \\
\hline \multicolumn{7}{|c|}{ No. of organs involved } \\
\hline 1 & 2 & 2.7 & 1 & 1.3 & 3 & 2.0 \\
\hline 2 & 7 & 9.6 & 4 & 5.3 & 11 & 7.4 \\
\hline$>2$ & 65 & 89 & 70 & 93.3 & 135 & 91.2 \\
\hline \multicolumn{7}{|l|}{ Prior therapy } \\
\hline XELOX & 45 & 61.7 & 49 & 65.3 & 94 & 63.5 \\
\hline SOX & 13 & 17.8 & 12 & 16 & 25 & 16.9 \\
\hline ECF like & 13 & 17.8 & 13 & 17.3 & 26 & 17.6 \\
\hline other & 2 & 2.7 & 1 & 1.3 & 3 & 2.0 \\
\hline
\end{tabular}


Table 2. Best Overall Response Rate

\begin{tabular}{|lllll|}
\hline & \multicolumn{4}{l}{ Treatment(No. of patients) } \\
& No. $(\mathrm{n}=73)$ & $\mathrm{P}(\mathrm{n}=75)$ \\
\hline Parameter & No & No. & $\%$ \\
\hline Overall response rate & 5 & 6.8 & 3 & 4 \\
\hline Complete response & 0 & 0 & 1 & 1.3 \\
\hline Partial response & 5 & 6.8 & 2 & 2.7 \\
\hline No change/stable disease & 36 & 49.3 & 24 & 32.0 \\
\hline Progressive disease & 32 & 43.8 & 48 & 64.0 \\
\hline Disease control rate & 41 & 56.2 & 27 & 36.0 \\
\hline
\end{tabular}

\section{Figures}




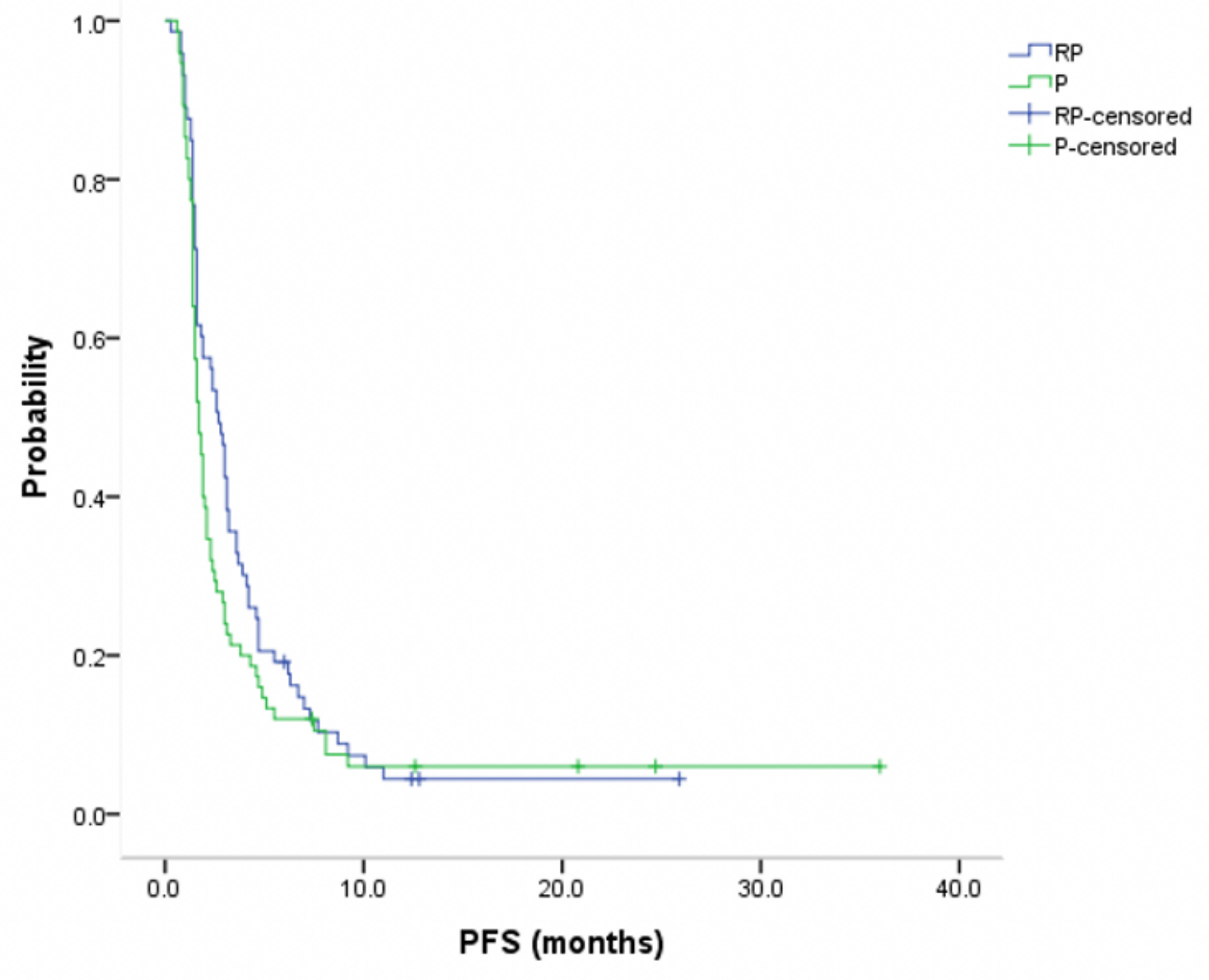

Figure 1

ITT,Kaplan-Meier estimates of time to progression survival among advanced gastric cancer patients treated with RP or P. 


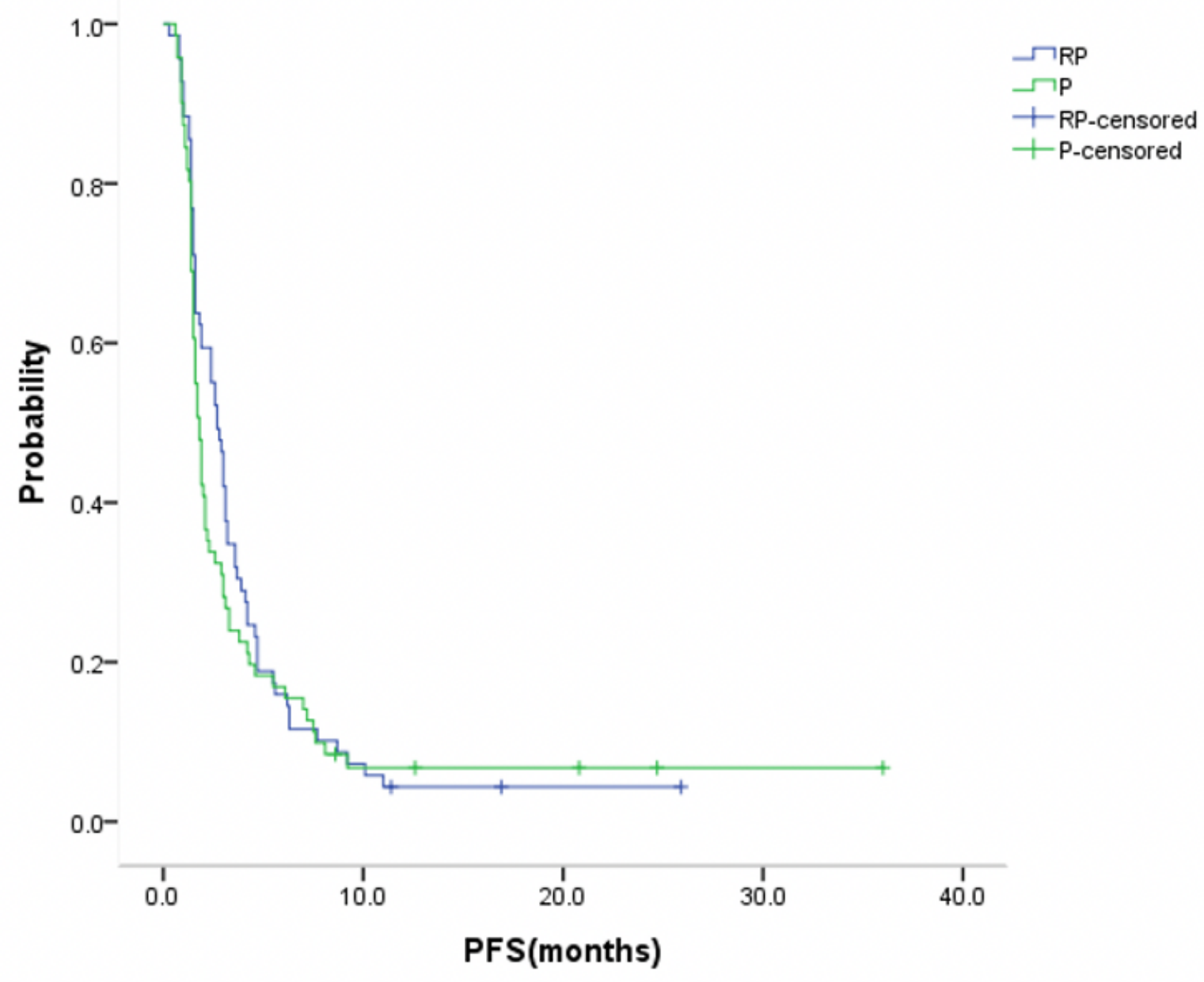

Figure 2

PP, Kaplan-Meier estimates of time to progression survival among advanced gastric cancer patients treated with RP or P. 


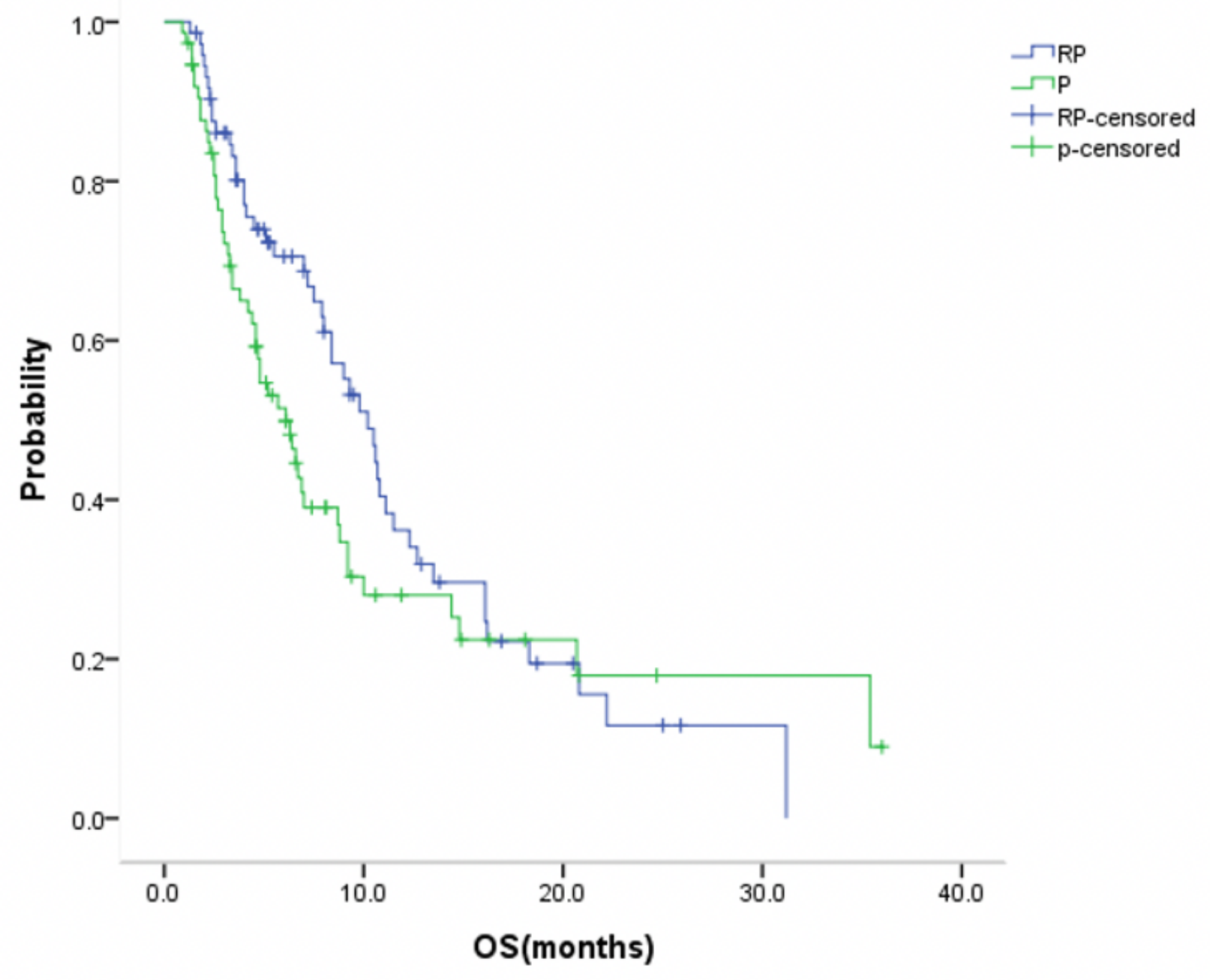

Figure 3

ITT, Kaplan-Meier estimates of time to overall survival among advanced gastric cancer patients treated with RP or P. 


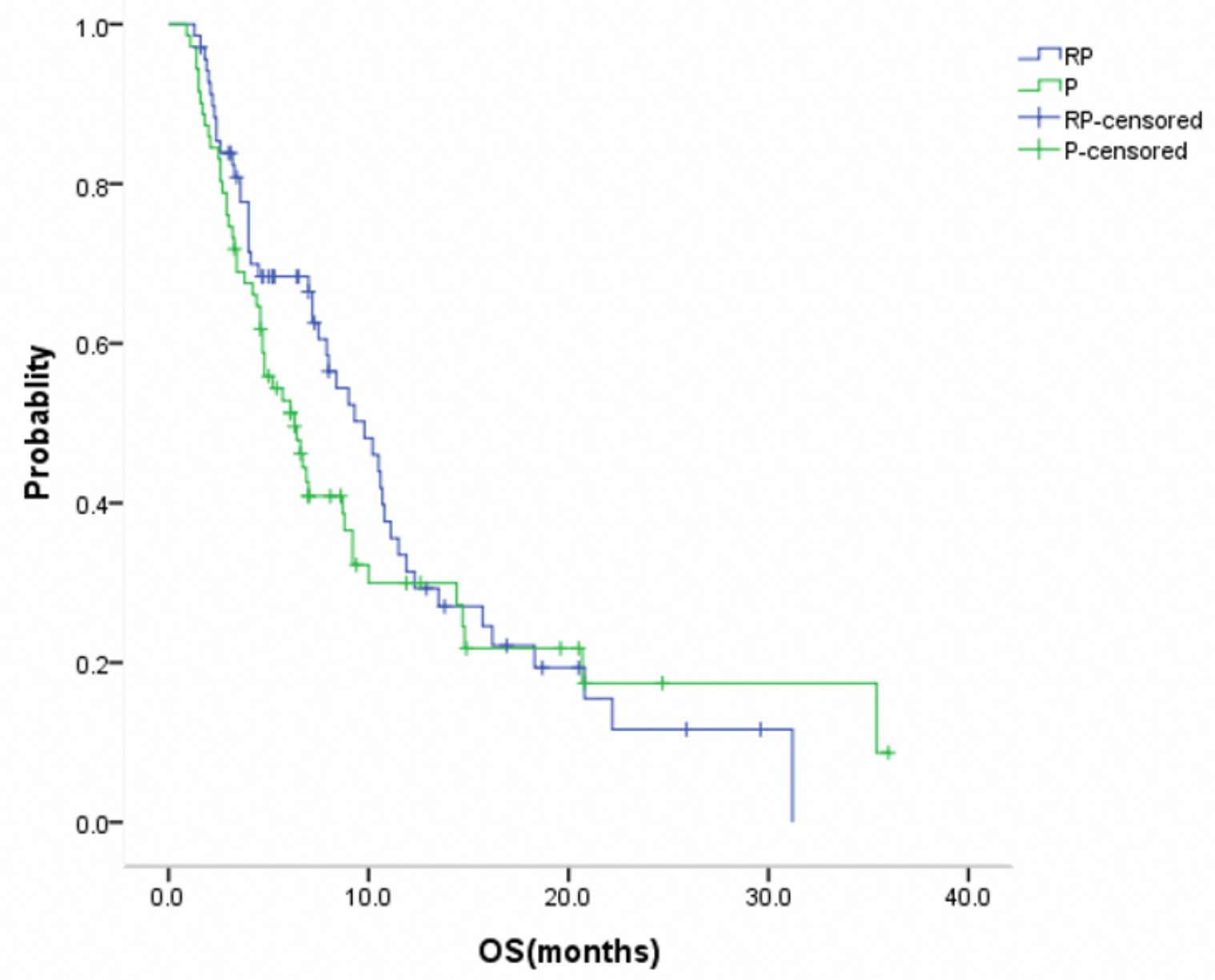

Figure 4

PP, Kaplan-Meier estimates of time to overall survival among advanced gastric cancer patients treated with RP or P. 